\title{
Carbon as a Simple Support for Redox Biocatalysis in Continuous Flow
}

\author{
Barnabas Poznansky, ${ }^{\S}$ Lisa A. Thompson, ${ }^{\S}$ Sarah A. Warren, Holly A. Reeve, ${ }^{*}$ and Kylie A. Vincent* \\ Cite This: Org. Process Res. Dev. 2020, 24, 2281-2287 \\ Read Online
}

ABSTRACT: A continuous packed bed reactor for NADH-dependent biocatalysis using enzymes co-immobilized on a simple carbon support was optimized to $100 \%$ conversion in a residence time of $30 \mathrm{~min}$. Conversion of pyruvate to lactate was achieved by co-immobilized lactate dehydrogenase and formate dehydrogenase, providing in situ cofactor recycling. Other metrics were also considered as optimization targets, such as low E factors between $2.5-11$ and space-time yields of up to $22.9 \mathrm{~g} \mathrm{~L}^{-1} \mathrm{~h}^{-1}$. The longterm stability of the biocatalytic reactor was also demonstrated, with full conversion maintained over more than $30 \mathrm{~h}$ of continuous operation.

KEYWORDS: biocatalysis, flow chemistry, cofactor recycling, immobilized enzyme, packed bed

\section{INTRODUCTION}

The push toward greener, more efficient methods for chemical production is currently a major focus of the pharmaceutical and fine-chemical industries, driven by economic, environmental, and regulatory factors. ${ }^{1-4}$ Biocatalysts are known for their excellent selectivity (removing the need for protection/ deprotection steps) under mild reaction conditions and are widely seen as a greener alternative to traditional chemical synthesis methods, ${ }^{5,6}$ particularly for chiral products. Protein evolution techniques are commonly used to expand the substrate scope and improve the stability of biocatalysts in order to increase their industrial viability.

Many useful redox enzymes are dependent on nicotinamide adenine dinucleotide cofactors $\left(\mathrm{NAD}^{+} / \mathrm{NADH}\right.$ or $\mathrm{NADP}^{+} /$ $\mathrm{NADPH}$ ) for operation. The reduced forms, $\mathrm{NAD}(\mathrm{P}) \mathrm{H}$, function as hydride donors to the large family of alcohol dehydrogenases (ketoreductases), which are well-established for the introduction of chiral alcohol moieties in pharmaceutical synthesis, ${ }^{7}$ as well as imine reductases for the synthesis of chiral amines ${ }^{8}$ and ene reductases for $\mathrm{C}=\mathrm{C}$ bond reductions. The high cost of these cofactors means that cofactor recycling systems are required. The most commonly used systems employ additional enzymes (glucose/formate/alcohol dehydrogenases) and sacrificial reagents (glucose/formate/isopropanol, respectively), which generate superstoichiometric quantities of carbon-based waste and lead to the requirement for continuous $\mathrm{pH}$ monitoring and adjustment in batch reactions.

Immobilization of biocatalysts can lead to improved stability and increase enzyme lifetimes. ${ }^{10-12}$ Recent advances in enzyme immobilization have exploited techniques such as HaloTag ${ }^{13}$ and histidine tagging of proteins as well as the use of a range of support materials, including resins, ${ }^{14}$ agarose, ${ }^{15}$ and microbeads. ${ }^{16}$ However, many of these enzyme immobilization techniques require expensive supports, modification of the support and/or enzyme, or lengthy immobilization times and can cause a significant loss of activity compared with the free enzyme in solution.

Flow chemistry is another powerful technique for greener, more efficient chemical production that has gained in importance in recent years. ${ }^{17-19}$ Flow reactors can offer improved heat and mass transfer and a smaller footprint compared with batch reactors for the same product yield. Flow chemistry also makes it easier to design and optimize scalable reaction methods and intensify reaction conditions, opening up a wider chemical space than is possible in batch reactions. ${ }^{20,21}$ Immobilization of biocatalysts makes them amenable to use in continuous flow packed bed reactors, wherein the solid catalyst is contained within a tubular reactor and the reaction solution is continuously pumped through it. The high ratio of catalyst to substrate achievable in packed bed reactors also often enables shorter reaction times and increased yields. Additionally, the constant removal of reaction solution can help to overcome substrate or product inhibition of the enzyme, which can be a common problem. Consequently, the number of examples of supported biocatalysis in flow is increasing. ${ }^{22,23}$

Existing examples of cofactor-dependent redox biocatalysis in flow often employ the cofactor recycling enzymes in solution, ${ }^{24,25}$ contributing to increased waste and cost for the process. However, there are a number of reports in which the enzyme responsible for the biotransformation and the cofactor recycling enzyme have been coimmobilized in flow reactors. ${ }^{15,16,26-29}$ Common problems include significant loss of activity, complex immobilization strategies, and low productivities.

Special Issue: Flow Chemistry Enabling Efficient Synthesis

Received: September 24, 2019

Published: January 31, 2020 
Here we demonstrate heterogeneous biocatalytic ketone reduction with in situ biocatalytic cofactor recycling using a dual-enzyme system supported on simple carbon particles in a continuous packed bed flow reactor. We chose carbon as a cheap and commercially available support, facilitating simple one-step enzyme immobilization via adsorption. ${ }^{30}$ There are a limited number of examples of the use of carbon as a support for biocatalysis, although it has been demonstrated as an electronic linker between enzymes for oxidation and reduction reactions using a range of carbon materials. ${ }^{31-33}$ Carbon is the standard support for heterogeneous metal-nanoparticle catalysis in both batch and flow reactors. The use of similar carbon supports could offer a route to implementing biocatalysis in industry-standard flow reactors.

\section{RESULTS AND DISCUSSION}

In this study we chose Black Pearls 2000 particles (Cabot Corporation) as the enzyme support material for the continuous flow process. This is an amorphous carbon black material with particles on the nanometer scale that agglomerate to form larger aggregates with high nanoscale porosity. ${ }^{34}$ They present a very high surface area $\left(>1000 \mathrm{~m}^{2} \mathrm{~g}^{-1}\right)$ for enzyme adsorption, and we have found that this carbon type functions well as a support material for many different enzymes under batch conditions. ${ }^{33,35,36}$

The conversion of pyruvate to lactate using $\mathrm{NADH}$ dependent lactate dehydrogenase $(\mathrm{LDH})$ was chosen as the test reaction (Scheme 1A). Cofactor regeneration was provided by the $\mathrm{NAD}^{+}$-dependent conversion of formate to

Scheme 1. (A) NADH-Dependent Biocatalytic Conversion of Pyruvate to Lactate; (B) Flow Reactor Setup ${ }^{a}$
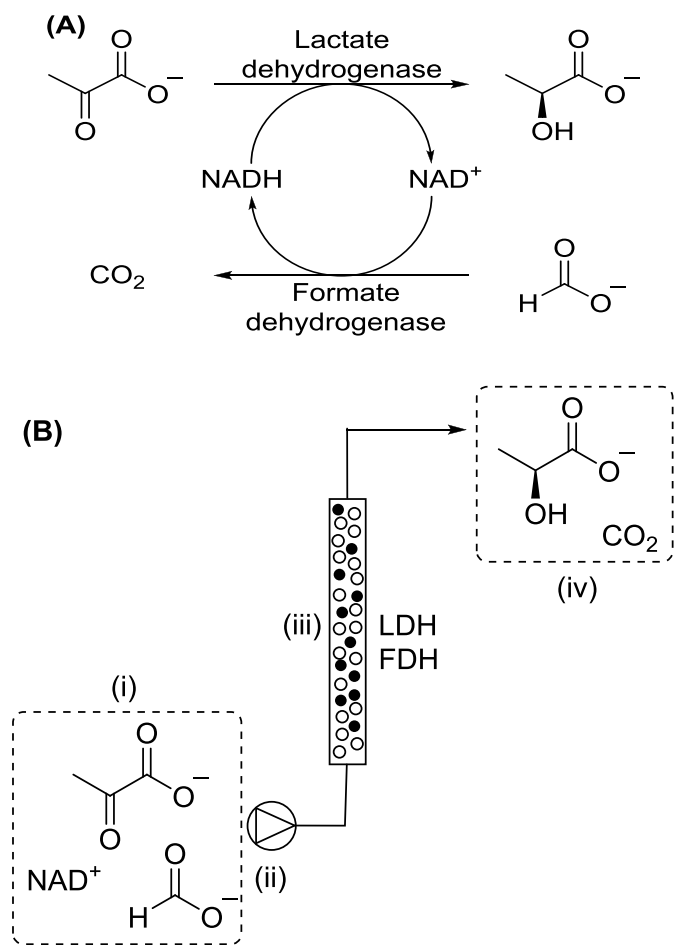

(iv)

${ }^{a}$ Legend for flow reactor setup: (i) reaction solution vessel; (ii) syringe pump; (iii) packed bed reactor; (iv) fraction collector; $\mathrm{LDH}=$ lactate dehydrogenase; FDH = formate dehydrogenase; $\mathbf{O}=$ enzymemodified carbon particle; $\mathrm{O}=$ glass bead.
$\mathrm{CO}_{2}$ using formate dehydrogenase (FDH), an enzyme that has been used extensively for $\mathrm{NADH}$ recycling, for example, in biocatalytic synthesis of pharmaceutical molecules. ${ }^{37}$ Existing examples of $\mathrm{FDH}$ cofactor recycling in flow mainly employ FDH in solution. ${ }^{24}$ The few examples of immobilized FDH in flow suffer from lengthy immobilizations, the use of noncommercial support materials, or the requirement of directed evolution of FDH for sufficient immobilization. ${ }^{38,39}$ Here we investigate simple one-step immobilization of FDH and LDH on carbon particles for application in a packed bed reactor.

The heterogeneous biocatalyst was prepared by coimmobilization of the two enzymes on Black Pearls 2000 particles via simple adsorption at $4{ }^{\circ} \mathrm{C}$ with no further modification of the carbon support or the enzymes. After $4 \mathrm{~h}$ the enzyme-modified particles were collected by centrifugation and removal of the supernatant solution containing any unadsorbed enzyme.

The enzyme immobilization efficiency and activity on the carbon support were determined in batch for the individual enzymes (see the Supporting Information (SI)). For LDH, $>99 \%$ immobilization on the carbon particles was achieved with an activity of 19 units $\mathrm{mg}^{-1}$ in a heterogeneous batch reaction. For FDH, 82\% immobilization on the carbon particles was achieved with an activity of 0.015 units $\mathrm{mg}^{-1}$ in a heterogeneous batch reaction.

For the flow reactor setup (Scheme 1B), biocatalyst particles were mixed with glass beads $(1 \mathrm{~mm})$ and manually packed into an Omnifit glass column (6.6 $\mathrm{mm}$ i.d., variable bed length). The enzyme-modified particles were mixed with glass beads to increase the volume of the solid support in the reactor and therefore allow a larger reactor column to be used. This was necessary to achieve the desired residence time (tRes) of 1030 min within the flow rate capability of the available pumps. Additionally, the use of a matrix material such as glass beads mixed with a heterogeneous catalyst in packed bed reactors is a common method to reduce the pressure drop across the reactor bed, particularly when very small catalyst particles are used. The reaction solution was pumped through the column using a continuous syringe pump (Asia, Syrris), and the components were connected using PTFE tubing ( $0.5 \mathrm{~mm}$ i.d.) and standard $1 / 4-28$ PTFE flangeless fittings. The reaction solution was collected at the reactor outlet using a BioRad model 2110 fraction collector.

Initially the effect of a flow stream on the enzyme immobilization was determined by pumping Tris- $\mathrm{HCl}$ buffer ( $50 \mathrm{mM}, \mathrm{pH} 8.0)$ through the packed column and monitoring the outlet solution by UV-vis spectroscopy for the presence of leached enzyme (see the SI for calibration curves and leaching data). Only $0.2 \%$ leaching of $\mathrm{LDH}$ was observed over $6 \mathrm{~h}$, demonstrating good retention of this enzyme on the carbon support. This is particularly significant because no chemical transformation or enzyme engineering was required for immobilization, only a simple adsorption procedure. For $\mathrm{FDH}$, a higher rate of leaching was observed: $6 \%$ leaching over $6 \mathrm{~h}$ and a total of $10 \%$ over $28 \mathrm{~h}$. In all of the reactions, the packed column was flushed with buffer prior to the start of the reaction in order to ensure that this initial amount of leached material was removed before the start of the reaction.

The packed bed reactor was tested for the conversion of pyruvate to lactate with in situ cofactor recycling. The reactor was set up with a single liquid feed containing different concentrations of sodium pyruvate, $\mathrm{NAD}^{+}$, and sodium formate in Tris- $\mathrm{HCl}$ buffer $(50 \mathrm{mM}, \mathrm{pH}$ 8.0). For each 
(A)

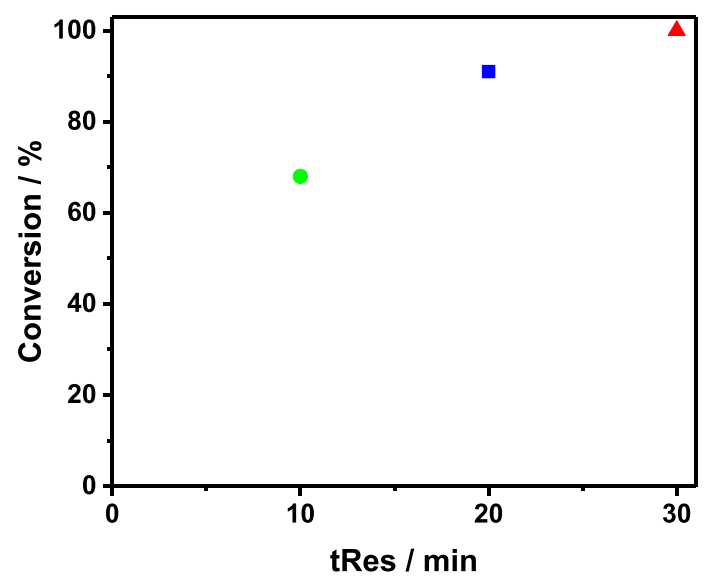

(C)

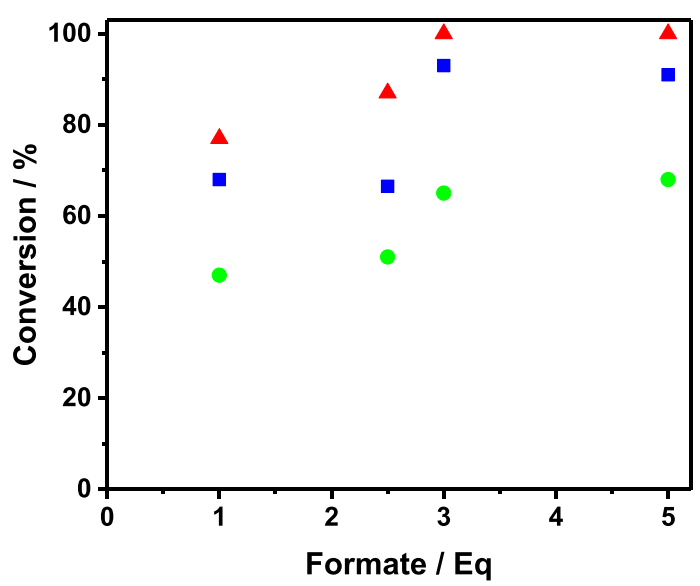

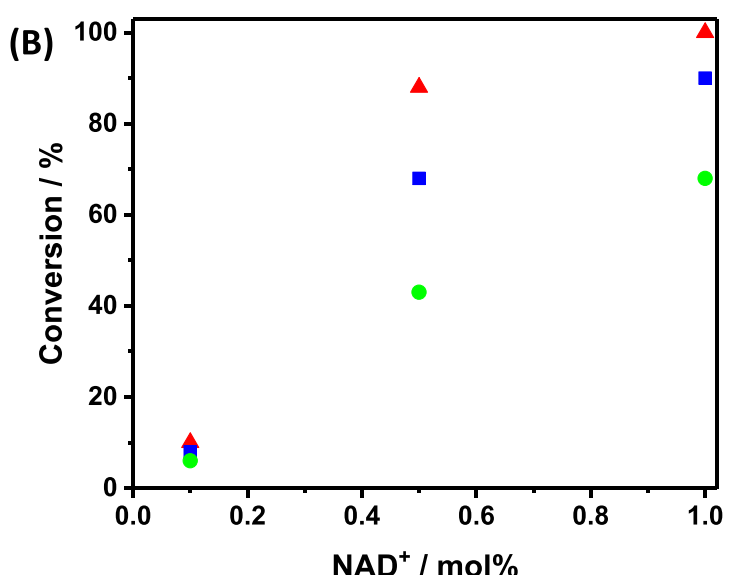

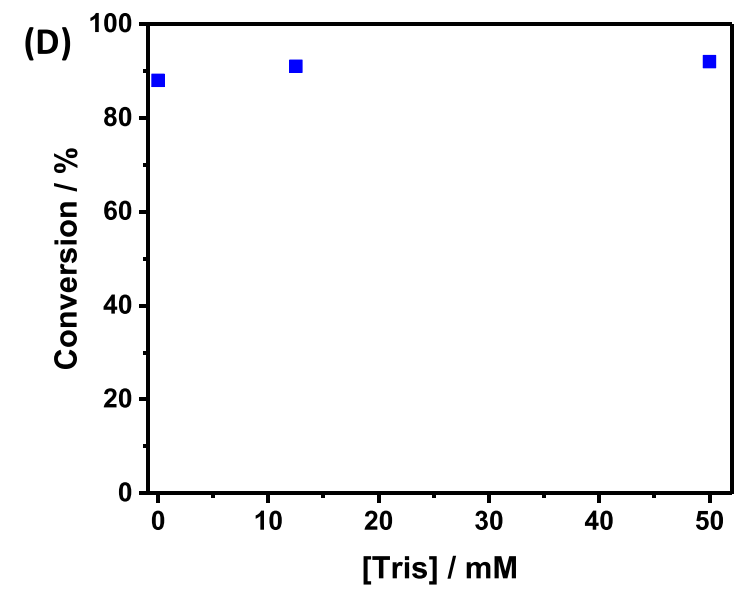

Figure 1. Effect of varying (A) tRes, (B) the $\mathrm{NAD}^{+} \mathrm{mol} \%,(\mathrm{C})$ the number of equivalents of formate, and (D) the Tris- $\mathrm{HCl}$ buffer concentration on the conversion of pyruvate to lactate in the continuous packed bed reactor. Unless otherwise stated, all experiments were performed with 50 $\mathrm{mM}$ pyruvate, 5 equiv of formate, $1 \mathrm{~mol} \% \mathrm{NAD}^{+}, 50 \mathrm{mM}$ Tris- $\mathrm{HCl}$ buffer (pH 8.0), $3 \mathrm{mg}$ of LDH, $30 \mathrm{mg}$ of FDH, and $30 \mathrm{mg}$ of carbon at room temperature. Symbols: green circles, tRes $=10 \mathrm{~min}$; blue squares, tRes $=20 \mathrm{~min}$; red triangles, $\mathrm{tRes}=30 \mathrm{~min}$.

experiment, the reactor was run until a steady state was reached (approximately 3-5 reactor volumes), and then multiple samples were collected for ${ }^{1} \mathrm{H}$ NMR analysis. The value quoted for the conversion was an average across the samples analyzed at steady state under a specific set of reactor conditions (minimum of three data points). Initial testing was carried out in the flow reactor for the conversion of $10 \mathrm{mM}$ pyruvate to lactate in order to determine an appropriate LDH:FDH:carbon ratio. This provided loadings of $3 \mathrm{mg}$ of $\mathrm{LDH}, 30 \mathrm{mg}$ of $\mathrm{FDH}$, and $30 \mathrm{mg}$ of carbon, which were used for all further experiments.

Optimization of the reaction conditions in flow was carried out by variation of tRes, the number of equivalents of formate, and the mole percent of $\mathrm{NAD}^{+}$in order to maximize the conversion of $50 \mathrm{mM}$ pyruvate (Figure 1). The operational window for the variables was determined by a set of desired characteristics: tRes to be no longer than $30 \mathrm{~min}$ (for reasonable productivities), the number of equivalents of formate to be no greater than 5 (to limit the waste contribution), and the $\mathrm{NAD}^{+}$loading to be no greater than $1 \mathrm{~mol} \%$ (for viable cofactor turnover numbers and to limit the cofactor contribution to waste). The results are summarized in Figure 1.

Variation of tRes from 10 to $30 \mathrm{~min}$ showed an increase in conversion up to $>99 \%$ at the longest residence time (Figure 1A), consistent with the increased contact time between the reaction solution and the catalyst. As expected, increasing the amount of $\mathrm{NAD}^{+}$from 0.01 to $1 \mathrm{~mol} \%$ led to an increase in conversion up to full conversion at the highest cofactor loading at a tRes of $30 \mathrm{~min}$ (Figure $1 \mathrm{~B}$ ). At $0.5 \mathrm{~mol} \% \mathrm{NAD}^{+}, 88 \%$ conversion was achieved, corresponding to a cofactor turnover number of 176 . Increasing the number of equivalents of formate from 1 to 2.5 had little effect on the conversion (approximately 70\%), but more than 90\% conversion was achieved with 3 and 5 equiv (Figure 1C) at a tRes of $20 \mathrm{~min}$. This dependence appeared to be consistent across all of the different tRes tested. Lowering the buffer concentration from 50 to $12.5 \mathrm{mM}$ ( $\mathrm{pH} 8.0$ ) and then using unbuffered $\mathrm{H}_{2} \mathrm{O}$ had a negligible effect on the outcome of the reaction (Figure 1D). Being able to run the reaction in pure $\mathrm{H}_{2} \mathrm{O}$ may overcome any enzyme compatibility issues with $\mathrm{pH}$ or buffer and would reduce waste and simplify the process. From these studies, the operating conditions to achieve optimum conversion were tRes $=30 \mathrm{~min}, 1 \mathrm{~mol} \% \mathrm{NAD}^{+}$, and 3 equiv of formate.

The results in Figure 1 detail optimization of the system for conversion. When additional responses such as productivity (space-time yield, STY) and waste (measured as the E factor) are considered, ${ }^{40}$ more complete process optimization can be achieved.

The data points were used to generate predictive models employing statistical design software (JMP 14, available from $\mathrm{SAS}$ ), with the reaction parameters (tRes, $\mathrm{NAD}^{+}$mol \%, equiv of formate, and buffer concentration) used as inputs. Models were created for predicted conversion, STY, and E factor. The 

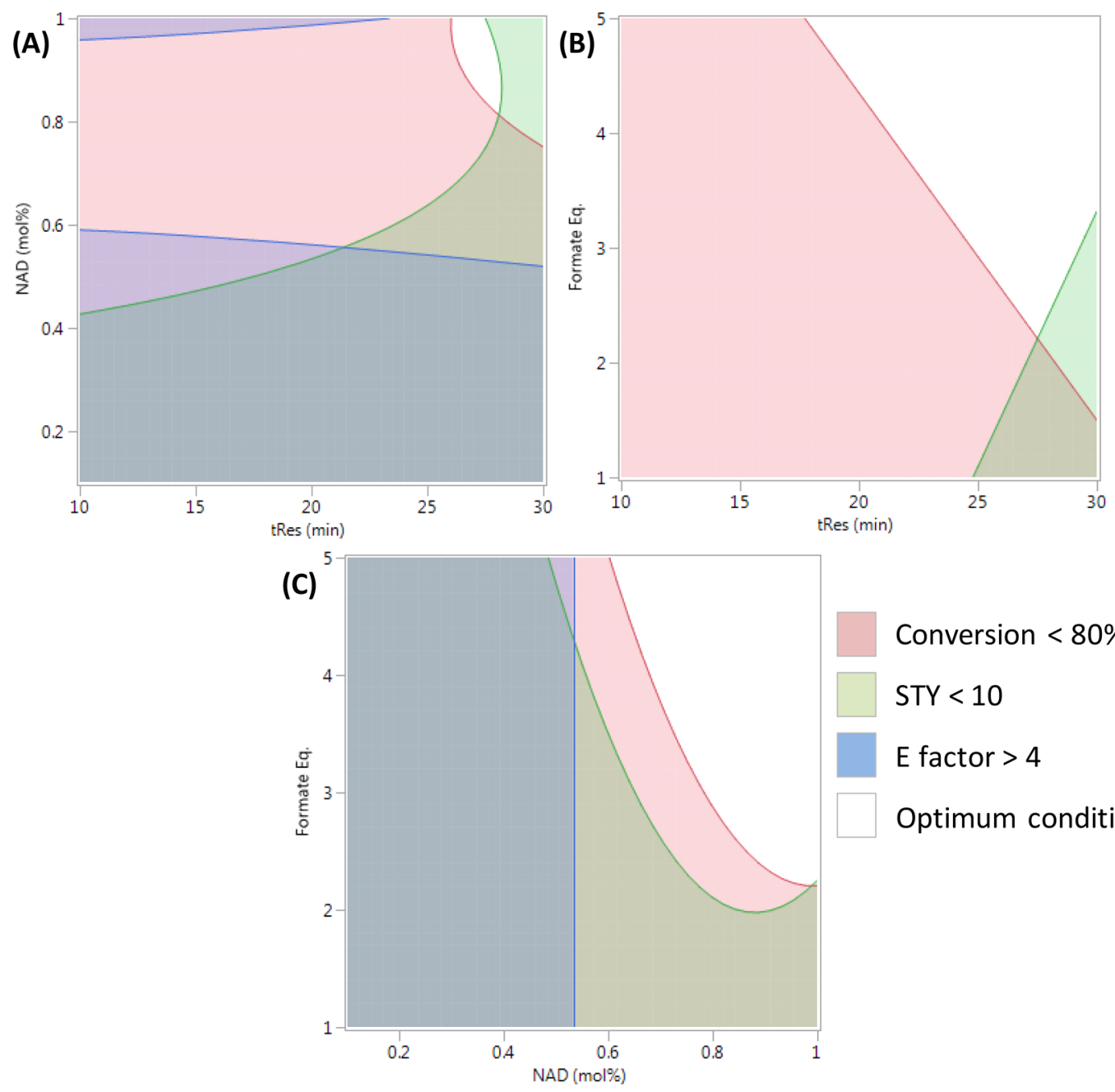

Conversion $<80 \%$

STY $<10$

\section{E factor $>4$}

Optimum conditions

Figure 2. Contour profiles showing the combination of predicted responses for conversion (red), STY (green), and E factor (blue) for the continuous biocatalytic conversion of pyruvate to lactate for various operating conditions: (A) tRes vs NAD ${ }^{+}$; (B) tRes vs formate; (C) NAD ${ }^{+}$vs formate. Colored sections denote the operating conditions where the desired response limit is not achieved, and the white sections denote the optimum operating windows in which all of the desired response limits are achieved. The profiles were generated using the statistical design software JMP 14.

full models generated are presented and discussed in SI section S7. From the models, the predicted responses for conversion (red), STY (green), and E factor (blue) were combined, and contour profiles were generated across the parameter ranges explored (Figure 2). The desired response limits were set to conversion $>80 \%$, STY $>10 \mathrm{~g} \mathrm{~L}^{-1} \mathrm{~h}^{-1}$, and E factor $<4$ in order to determine the predicted operating window within which all of these selected criteria are met (white areas of the contour profiles). Generally, to optimize for STY, a shorter tRes would have been more favorable, as more material is processed in a shorter time. In contrast, to optimize for $\mathrm{E}$ factor and conversion a longer tRes is favorable, as the longer exposure to the catalyst leads to higher conversion, and therefore, less unreacted material is left over as waste. All three responses would have been improved by the higher driving force provided by higher $\mathrm{NAD}^{+} \mathrm{mol} \%$ and more equivalents of formate, as this leads to higher conversion, higher productivity per unit time, and less waste due to unreacted starting material. However, use of formate in too high an excess would begin to negatively impact the $\mathrm{E}$ factor. From the contour profiles it can be determined that the reaction parameters required for operation in the optimum window for all three responses are
tRes $=25-30 \mathrm{~min}, 0.8-1 \mathrm{~mol} \% \mathrm{NAD}^{+}$, and $2.5-5$ equiv of formate. These ranges encompass the optimized parameter values for conversion while suggesting that lower values could be used without negatively impacting the process. Additionally, if the main optimization focus for the process were shifted to another specific response (e.g., the E factor), this information could be used to reassess the optimum operating parameters and provide new ranges.

The longer-term stability of the biocatalytic reactor was also investigated using the optimal conditions for high conversion: $50 \mathrm{mM}$ pyruvate, 5 equiv of formate, $1 \mathrm{~mol} \% \mathrm{NAD}^{+}$, tRes $=30$ $\mathrm{min}$, and $50 \mathrm{mM}$ Tris- $\mathrm{HCl}$ buffer $(\mathrm{pH} 8.0)$. In this case, enzymes were immobilized on carbon within the column to prevent loss of catalyst during transfer into the reactor column and for ease of use, allowing for catalyst preparation and reaction to take place in the same reactor column. The results in Figure 3 show that full conversion was maintained for $30 \mathrm{~h}$, demonstrating the viability of the biocatalyst over extended operating periods. During this $30 \mathrm{~h}$ of operation, a STY, E factor, and productivity of $11.1 \mathrm{~g}_{\text {lactate }} \mathrm{L}^{-1} \mathrm{~h}^{-1}, 4.4$, and 34.9 $\mu \mathrm{mol}_{\text {lactate }} \min ^{-1} \mathrm{~g}_{\text {support }}^{-1}$ were maintained, respectively. The effective activities of the coupled FDH and $\mathrm{LDH}$ in this flow 


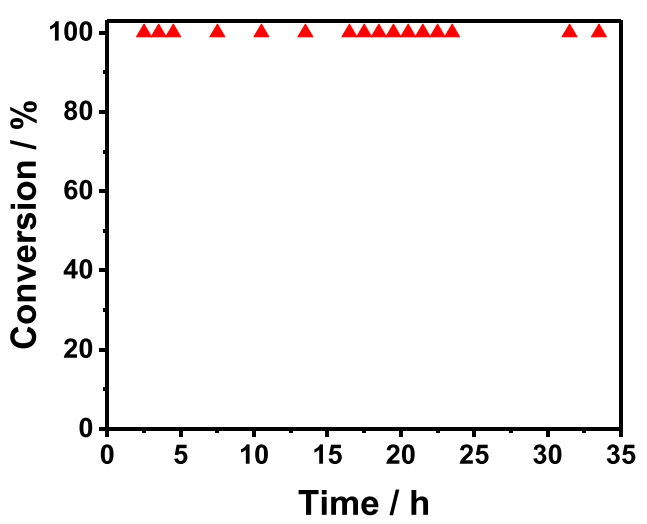

Figure 3. Long-term operation of the continuous biocatalytic packed bed reactor for the conversion of pyruvate to lactate. Conditions: 50 $\mathrm{mM}$ pyruvate, 5 equiv of formate, $1 \mathrm{~mol} \% \mathrm{NAD}^{+}, 50 \mathrm{mM}$ Tris- $\mathrm{HCl}$

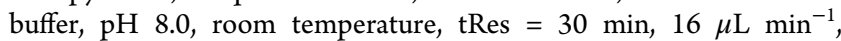
reactor volume $=0.48 \mathrm{~mL}$.

experiment were 0.03 and 0.25 units $\mathrm{mg}^{-1}$, respectively. These values can be compared with the activities achieved in the single-enzyme immobilization studies ( 0.015 and 19 units $\mathrm{mg}^{-1}$ for FDH and $\mathrm{LDH}$, respectively; SI section S3). FDH had a higher effective activity when coupled to $\mathrm{LDH}$ in the flow system, but LDH was significantly less active than expected. To determine whether the overall reaction was limited by $\mathrm{FDH}$, the $\mathrm{LDH}$ loading was decreased from $3 \mathrm{mg}$ to $0.1 \mathrm{mg}$ at constant FDH loading $(30 \mathrm{mg})$. The activity of LDH in the resulting catalyst was determined to be 10.7 units $\mathrm{mg}^{-1}$, which is much closer to that observed in the immobilization studies, showing that the flow process could be further optimized with respect to the enzyme loading.

At the end of a separate $24 \mathrm{~h}$ run, the packed column reactor was flushed with Tris- $\mathrm{HCl}$ buffer $(50 \mathrm{mM}, \mathrm{pH} 8.0)$ and stored at $4{ }^{\circ} \mathrm{C}$ overnight. The reactor was then reused and achieved $72 \%$ conversion under the same reaction conditions (data are provided in the SI). This demonstrates the potential for reusability and stability of the catalyst column upon further optimization of the storage conditions.

A comparative batch reaction $(24 \mathrm{~mL}, 24 \mathrm{~h})$ was carried out using the same catalyst loading as in the flow reactor (Figure S10), and key parameters are compared with those for the flow process (Table S5). After $24 \mathrm{~h}$ in batch, $96 \%$ conversion was achieved, giving a comparable activity $\left(\mathrm{mg}_{\text {lactate }} \mathrm{h}^{-1}\right)$ and the same E factor (4.4) as the flow process. The STY was $0.23 \mathrm{~g}$ $\mathrm{L}^{-1} \mathrm{~h}^{-1}$ for the batch process compared with $11.2 \mathrm{~g} \mathrm{~L}^{-1} \mathrm{~h}^{-1}$ for the flow process, demonstrating the higher productivity that can be achieved using the low flow reactor volume $(0.48 \mathrm{~mL}$ vs $24 \mathrm{~mL}$ in batch). The enzyme activities recorded were very similar, with slightly higher initial activities recorded in the batch reaction.

\section{CONCLUSIONS}

We have presented the use of a simple carbon support for straightforward co-immobilization of NADH-dependent $\mathrm{LDH}$ with FDH to facilitate ketone reduction with in situ cofactor recycling in a continuous packed bed reactor. FDH is wellestablished as a cofactor recycling system for $\mathrm{NADH}$ dependent enzymes, suggesting that it should be possible to translate many other biotransformations requiring $\mathrm{NADH}$ into flow. Variation of reaction parameters generated a set of optimum reactor conditions to maximize conversion ( $\mathrm{tRes}=$
$30 \mathrm{~min}, 1 \mathrm{~mol} \% \mathrm{NAD}^{+}, 5$ equiv of formate). Further interrogation of the results aided by statistical modeling generated an optimum operating window for the process in terms of additional process metrics (STY and E factor) in combination with conversion. The longer-term stability of the biocatalytic reactor was demonstrated, with high conversion and productivity achieved in the flow reactor for more than 30 h. The methodology investigated here displays significant advantages over existing methods in terms of the simple, cheap, and readily available carbon support and the one-step immobilization strategy, which requires no modification of the support or the enzymes. Therefore, this biocatalytic system overcomes some of the key challenges associated with the adoption of biocatalysis for greener chemical production, namely, enzyme stability and cofactor recycling, and shows that by considering multiple targets for optimization, the biocatalytic reactor conditions can be tailored to the desired process outcome.

\section{EXPERIMENTAL SECTION}

General. Sodium pyruvate (Sigma), sodium formate (Sigma), $\mathrm{NAD}^{+}$(Prozomix), carbon black particles (Black Pearls 2000, Cabot Corporation), and Trizma-base (Sigma) were used as received without further purification. All solutions were prepared with Milli-Q water (Millipore, $18 \mathrm{M} \Omega \mathrm{cm}$ ). Lactate dehydrogenase (from rabbit muscle, Merck) and formate dehydrogenase (FDH-102, Johnson Matthey) were used as supplied. UV-vis spectra were recorded using an Agilent Cary 60 spectrophotometer. ${ }^{1} \mathrm{H}$ NMR spectroscopy was performed using a Bruker Avance III HD nanobay spectrometer $(400 \mathrm{MHz})$, with the addition of $10 \% \mathrm{D}_{2} \mathrm{O}$ to all samples. Reaction products were determined by comparison to analytical standards.

Preparation of the Supported Biocatalyst. Carbon particles (30 mg, Black Pearls 2000, Cabot Corporation) were suspended in $1.5 \mathrm{~mL}$ of Tris- $\mathrm{HCl}$ buffer $(50 \mathrm{mM}, \mathrm{pH} 8.0)$ and sonicated for $75 \mathrm{~min}$. A mixture of $\mathrm{LDH}(3 \mathrm{mg})$ and $\mathrm{FDH}(30$ $\mathrm{mg}$ ) was added to the $1.5 \mathrm{~mL}$ carbon suspension, and the enzymes allowed to adsorb at $4{ }^{\circ} \mathrm{C}$. After $4 \mathrm{~h}$, the mixture was centrifuged, and the supernatant solution was removed to yield the biocatalytic particles.

Enzyme Immobilization Efficiency. The immobilization efficiency was determined by analysis of the supernatant recovered from the enzyme immobilization procedure by measurement of the UV-vis absorbance at $280 \mathrm{~nm}$ and comparison to calibration curves (see the SI) to determine the protein concentration relative to the amount of added protein.

Analysis of Immobilized Enzyme Activity. The enzyme activity was determined by monitoring the conversion of $\mathrm{NADH}$ to $\mathrm{NAD}^{+}$over time by UV-vis spectroscopy (see the SI). The catalyst particles were added to a cuvette $(1 \mathrm{~mL}$, Hellma) containing $\mathrm{NADH}(0.1 \mathrm{mM})$ and either sodium pyruvate $(0.1 \mathrm{mM})$ or sodium formate $(0.5 \mathrm{mM})$ in Tris- $\mathrm{HCl}$ buffer ( $50 \mathrm{mM}, \mathrm{pH} 8.0,1 \mathrm{~mL}$ total volume). The ratio of peaks at 260 and $340 \mathrm{~nm}$ was then used to calculate the enzyme activities after comparison to calibration curves. ${ }^{33}$

Continuous Packed Bed Reactor Setup. An Omnifit glass column ( $6.6 \mathrm{~mm}$ i.d., variable bed length) was manually packed with the catalyst particles and glass beads $(1 \mathrm{~mm})$. For all experiments, the Omnifit column bed length was adjusted to give a total bed volume of $1.02 \mathrm{~mL}$. The actual reactor volume was then calculated using the void fraction method, ${ }^{41}$ where the reactor volume is the total bed volume minus the 
space filled by the catalyst, as calculated by the difference in column mass before and after filling with water (see the SI). The column was connected to the syringe pump (Asia, Syrris) using PTFE tubing $(0.5 \mathrm{~mm}$ i.d.) and $1 / 4$-28 PTFE flangeless fittings. Samples were collected at the reactor outlet using a BioRad model 2110 fraction collector.

Biocatalytic Production of Lactate in the Continuous Packed Bed Reactor. Sodium pyruvate $(50 \mathrm{mM}), \mathrm{NAD}^{+}$ (0.05-0.5 mM), and sodium formate $(50-250 \mathrm{mM})$ were dissolved in Tris- $\mathrm{HCl}$ buffer $(50 \mathrm{mM}, \mathrm{pH} 8.0)$, and the reaction solution was pumped through the packed bed reactor at flow rates between 17.2 and $51.6 \mu \mathrm{L} \mathrm{min}^{-1}$ (tRes $=10-30$ $\mathrm{min})$. Once the reactor reached a steady state, samples were collected and analyzed by ${ }^{1} \mathrm{H}$ NMR spectroscopy.

\section{ASSOCIATED CONTENT}

\section{SI Supporting Information}

The Supporting Information is available free of charge at https://pubs.acs.org/doi/10.1021/acs.oprd.9b00410.

Immobilization efficiency data and calibration curves, enzyme activity data, enzyme leaching data, packed column reuse data, JMP models, and NMR spectra (PDF)

\section{AUTHOR INFORMATION}

\section{Corresponding Authors}

Holly A. Reeve - Department of Chemistry, University of Oxford, Oxford OX1 3QR, U.K.; (1) orcid.org/0000-00015855-651X; Email: holly.reeve@chem.ox.ac.uk

Kylie A. Vincent - Department of Chemistry, University of Oxford, Oxford OX1 3QR, U.K.; (1) orcid.org/0000-00016444-9382; Email: kylie.vincent@chem.ox.ac.uk

\section{Authors}

Barnabas Poznansky - Department of Chemistry, University of Oxford, Oxford OX1 3QR, U.K.

Lisa A. Thompson - Department of Chemistry, University of Oxford, Oxford OX1 3QR, U.K.; (1) orcid.org/0000-00031128-7927

Sarah A. Warren - Dr. Reddy's Laboratories Ltd., Cambridge CB4 OPE, U.K.

Complete contact information is available at:

https://pubs.acs.org/10.1021/acs.oprd.9b00410

\section{Author Contributions}

${ }^{\S}$ B.P. and L.A.T. contributed equally. All of the authors helped to design the experiments. B.P. performed the experiments. B.P. and L.A.T. analyzed the data. All of the authors contributed to writing and approved the final version of the manuscript.

\section{Funding}

The research of K.A.V., H.A.R., and L.A.T. was supported by Engineering and Physical Sciences Research Council (EPSRC) IB Catalyst Award EP/N013514/1. B.P. was supported by iCASE funding from the Biotechnology and Biological Sciences Research Council (BBSRC,Grant BB/M011224/1), with support from Dr. Reddy's Laboratories.

\section{Notes}

The authors declare no competing financial interest.

\section{ACKNOWLEDGMENTS}

Dr. Beatriz Dominguez (Johnson Matthey) is gratefully acknowledged for providing FDH.

\section{ABBREVIATIONS}

$\mathrm{LDH}$, lactate dehydrogenase; $\mathrm{FDH}$, formate dehydrogenase; i.d., inner diameter; PTFE, polytetrafluoroethylene; tRes, residence time; STY, space-time yield

\section{REFERENCES}

(1) Anastas, P. T.; Warner, J. C. Green Chemistry: Theory and Practice, 1st ed.; Oxford University Press, 1998.

(2) Jiménez-González, C.; Poechlauer, P.; Broxterman, Q. B.; Yang, B.-S.; am Ende, D.; Baird, J.; Bertsch, C.; Hannah, R. E.; Dell'Orco, P.; Noorman, H.; Yee, S.; Reintjens, R.; Wells, A.; Massonneau, V.; Manley, J. Key Green Engineering Research Areas for Sustainable Manufacturing: A Perspective from Pharmaceutical and Fine Chemicals Manufacturers. Org. Process Res. Dev. 2011, 15, 900-911.

(3) Ciriminna, R.; Pagliaro, M. Green Chemistry in the Fine Chemicals and Pharmaceutical Industries. Org. Process Res. Dev. 2013, 17, 1479-1484.

(4) Bryan, M. C.; Dunn, P. J.; Entwistle, D.; Gallou, F.; Koenig, S. G.; Hayler, J. D.; Hickey, M. R.; Hughes, S.; Kopach, M. E.; Moine, G.; Richardson, P.; Roschangar, F.; Steven, A.; Weiberth, F. J. Key Green Chemistry research areas from a pharmaceutical manufacturers' perspective revisited. Green Chem. 2018, 20, 5082-5103.

(5) Woodley, J. M. New opportunities for biocatalysis: making pharmaceutical processes greener. Trends Biotechnol. 2008, 26, 321327.

(6) Sheldon, R. A.; Woodley, J. M. Role of Biocatalysis in Sustainable Chemistry. Chem. Rev. 2018, 118, 801-838.

(7) Prier, C. K.; Kosjek, B. Recent Preparative Applications of Redox Enzymes. Curr. Opin. Chem. Biol. 2019, 49, 105-112.

(8) Mangas-Sanchez, J.; France, S. P.; Montgomery, S. L.; Aleku, G. A.; Man, H.; Sharma, M.; Ramsden, J. I.; Grogan, G.; Turner, N. J. Imine Reductases (IREDs). Curr. Opin. Chem. Biol. 2017, 37, 19-25.

(9) Toogood, H. S.; Scrutton, N. S. Discovery, Characterization, Engineering, and Applications of Ene-Reductases for Industrial Biocatalysis. ACS Catal. 2018, 8, 3532-3549.

(10) Sheldon, R. A.; van Pelt, S. Enzyme immobilisation in biocatalysis: why, what and how. Chem. Soc. Rev. 2013, 42, 62236235.

(11) Rodrigues, R. C.; Ortiz, C.; Berenguer-Murcia, Á.; Torres, R.; Fernández-Lafuente, R. Modifying enzyme activity and selectivity by immobilization. Chem. Soc. Rev. 2013, 42, 6290-6307.

(12) Liese, A.; Hilterhaus, L. Evaluation of immobilized enzymes for industrial applications. Chem. Soc. Rev. 2013, 42, 6236-6249.

(13) Döbber, J.; Pohl, M. HaloTag ${ }^{\text {TM }}$ : Evaluation of a covalent onestep immobilization for biocatalysis. J. Biotechnol. 2017, 241, 170174.

(14) Contente, M. L.; Dall'Oglio, F.; Tamborini, L.; Molinari, F.; Paradisi, F. Highly Efficient Oxidation of Amines to Aldehydes with Flow-based Biocatalysis. ChemCatChem 2017, 9, 3843-3848.

(15) Dall'Oglio, F.; Contente, M. L.; Conti, P.; Molinari, F.; Monfredi, D.; Pinto, A.; Romano, D.; Ubiali, D.; Tamborini, L.; Serra, I. Flow-based stereoselective reduction of ketones using an immobilized ketoreductase/glucose dehydrogenase mixed bed system. Catal. Commun. 2017, 93, 29-32.

(16) Peschke, T.; Skoupi, M.; Burgahn, T.; Gallus, S.; Ahmed, I.; Rabe, K. S.; Niemeyer, C. M. Self-Immobilizing Fusion Enzymes for Compartmentalized Biocatalysis. ACS Catal. 2017, 7, 7866-7872.

(17) Plutschack, M. B.; Pieber, B.; Gilmore, K.; Seeberger, P. H. The Hitchhiker's Guide to Flow Chemistry. Chem. Rev. 2017, 117, 11796-11893.

(18) Bogdan, A. R.; Dombrowski, A. W. Emerging Trends in Flow Chemistry and Applications to the Pharmaceutical Industry. J. Med. Chem. 2019, 62, 6422-6468. 
(19) Rogers, L.; Jensen, K. F. Continuous manufacturing - the Green Chemistry promise? Green Chem. 2019, 21, 3481-3498.

(20) Hessel, V.; Kralisch, D.; Kockmann, N.; Noël, T.; Wang, Q. Novel Process Windows for Enabling, Accelerating, and Uplifting Flow Chemistry. ChemSusChem 2013, 6, 746-789.

(21) Gutmann, B.; Kappe, C. O. Forbidden chemistries - paths to a sustainable future engaging continuous processing. J. Flow Chem. 2017, 7, 65-71.

(22) Thompson, M. P.; Peñafiel, I.; Cosgrove, S. C.; Turner, N. J. Biocatalysis Using Immobilized Enzymes in Continuous Flow for the Synthesis of Fine Chemicals. Org. Process Res. Dev. 2019, 23, 9-18.

(23) Tamborini, L.; Fernandes, P.; Paradisi, F.; Molinari, F. Flow Bioreactors as Complementary Tools for Biocatalytic Process Intensification. Trends Biotechnol. 2018, 36, 73-88.

(24) Tomaszewski, B.; Lloyd, R. C.; Warr, A. J.; Buehler, K.; Schmid, A. Regioselective Biocatalytic Aromatic Hydroxylation in a GasLiquid Multiphase Tube-in-Tube Reactor. ChemCatChem 2014, 6, 2567-2576.

(25) Karande, R.; Schmid, A.; Buehler, K. Miniaturizing Biocatalysis: Enzyme-Catalyzed Reactions in an Aqueous/Organic Segmented Flow Capillary Microreactor. Adv. Synth. Catal. 2011, 353, 25112521.

(26) Peschke, T.; Bitterwolf, P.; Gallus, S.; Hu, Y.; Oelschlaeger, C.; Willenbacher, N.; Rabe, K. S.; Niemeyer, C. M. Self-Assembling AllEnzyme Hydrogels for Flow Biocatalysis. Angew. Chem., Int. Ed. 2018, 57, 17028-17032.

(27) De Vitis, V.; Dall'Oglio, F.; Pinto, A.; De Micheli, C.; Molinari, F.; Conti, P.; Romano, D.; Tamborini, L. Chemoenzymatic Synthesis in Flow Reactors: A Rapid and Convenient Preparation of Captopril. ChemistryOpen 2017, 6, 668-673.

(28) Benítez-Mateos, A. I.; San Sebastian, E.; Ríos-Lombardía, N.; Morís, F.; González-Sabín, J.; López-Gallego, F. Asymmetric Reduction of Prochiral Ketones by Using Self-Sufficient Heterogeneous Biocatalysts Based on NADPH-Dependent Ketoreductases. Chem. - Eur. J. 2017, 23, 16843-16852.

(29) Zor, C.; Reeve, H. A.; Quinson, J.; Thompson, L. A.; Lonsdale, T. H.; Dillon, F.; Grobert, N.; Vincent, K. A. $\mathrm{H}_{2}$-Driven biocatalytic hydrogenation in continuous flow using enzyme-modified carbon nanotube columns. Chem. Commun. 2017, 53, 9839-9841.

(30) Thompson, L. A.; Rowbotham, J. S.; Reeve, H. A.; Zor, C.; Grobert, N.; Vincent, K. A. Biocatalytic hydrogenations on carbon supports. Methods Enzymol. 2020, 630, 303-325.

(31) Vincent, K. A.; Li, X.; Blanford, C. F.; Belsey, N. A.; Weiner, J. H.; Armstrong, F. A. Enzymatic catalysis on conducting graphite particles. Nat. Chem. Biol. 2007, 3, 761-762.

(32) Lazarus, O.; Woolerton, T. W.; Parkin, A.; Lukey, M. J.; Reisner, E.; Seravalli, J.; Pierce, E.; Ragsdale, S. W.; Sargent, F.; Armstrong, F. A. Water-Gas Shift Reaction Catalyzed by Redox Enzymes on Conducting Graphite Platelets. J. Am. Chem. Soc. 2009, 131, 14154-14155.

(33) Reeve, H. A.; Lauterbach, L.; Lenz, O.; Vincent, K. A. EnzymeModified Particles for Selective Biocatalytic Hydrogenation by Hydrogen-Driven NADH Recycling. ChemCatChem 2015, 7, 34803487.

(34) Quinson, J.; Hidalgo, R.; Ash, P. A.; Dillon, F.; Grobert, N.; Vincent, K. A. Comparison of carbon materials as electrodes for enzyme electrocatalysis: hydrogenase as a case study. Faraday Discuss. 2014, 172, 473-496.

(35) Reeve, H. A.; Ash, P. A.; Park, H. S.; Huang, A.; Posidias, M.; Tomlinson, C.; Lenz, O.; Vincent, K. A. Enzymes as Modular Catalysts for Redox Half-Reactions in $\mathrm{H}_{2}$ Powered Chemical Synthesis: From Biology to Technology. Biochem. J. 2017, 474, 215-230.

(36) Rowbotham, J. S.; Lenz, O.; Reeve, H. A.; Vincent, K. A. Bringing biocatalysis into the deuteration toolbox. ChemRxiv, December 4, 2019, ver 1. DOI: 10.26434/chemrxiv.7982864.v1.

(37) Patel, R. N. Synthesis of Chiral Pharmaceutical Intermediates by Biocatalysis. Coord. Chem. Rev. 2008, 252, 659-701.
(38) Velasco-Lozano, S.; da Silva, E. S.; Llop, J.; López-Gallego, F. Sustainable and Continuous Synthesis of Enantiopure 1-Amino Acids by Using a Versatile Immobilised Multienzyme System. ChemBioChem 2018, 19, 395-403.

(39) Gao, X.; Ni, K.; Zhao, C.; Ren, Y.; Wei, D. Enhancement of the activity of enzyme immobilized on polydopamine-coated iron oxide nanoparticles by rational orientation of formate dehydrogenase. $J$. Biotechnol. 2014, 188, 36-41.

(40) Sheldon, R. A. The E factor 25 years on: the rise of green chemistry and sustainability. Green Chem. 2017, 19, 18-43.

(41) Rodriguez-Colinas, B.; Fernandez-Arrojo, L.; Santos-Moriano, P.; Ballesteros, A.; Plou, F. Continuous Packed Bed Reactor with Immobilized $\beta$-Galactosidase for Production of Galactooligosaccharides (GOS). Catalysts 2016, 6, 189. 